\title{
Annual Risk of Tuberculosis Infection in Hellenic Air Force Recruits
}

\author{
Vlachou Garyfalia ${ }^{*}, 1$, Gerogianni Irini ${ }^{2}$, Skoufaras Vasilios ${ }^{3}$ and \\ Gourgoulianis Konstantinos ${ }^{2}$
}

\author{
${ }^{I}$ Department of Respiratory Medicine, General Panarkadian Hospital, Tripolis, Greece \\ ${ }^{2}$ Department of Respiratory Medicine, University of Thessaly School of Medicine, Larissa, Greece \\ ${ }^{3}$ Department of Respiratory Medicine, 251 Air Force General Hospital, Athens, Greece
}

\begin{abstract}
Background: The annual risk of Tuberculosis infection (ARTI) is a key indicator in epidemiology, of the extent of transmission in a community. There have been several suggested methods in order to evaluate the prevalence of Tuberculosis infection using tuberculin skin data. This survey estimates the ARTI in young Hellenic air force recruits. The effect of BCG vaccination has also been investigated.

Materials and Methods: During the period November 2006-November 2007 tuberculin skin tests were conducted to estimate the prevalence of mycobacterium tuberculosis infection and also to determine the ARTI. Tuberculin PPD-RT 23, dose 2 IU was used in 7.492 Greek air force military recruits with a mean age of 23.57 years. All recruits were examined for previous bacill Calmette-Guérin vaccination through BCG scar. A vast number of personal, epidemiological significance, data of the participants was collected.

Results: The ARTI was $0.2 \%$, in those who were not previously BCG vaccinated; this was derived from a tuberculin skin test cut-off point of $10 \mathrm{~mm}$. There were not any statistically significant differences, neither between urban and rural population concerning the positivity of the tuberculin skin test, nor among the population in recent contact with immigrants from high-incidence countries.

Conclusion: The estimated ARTI among non BCG vaccinated young Greek men is $0.2 \%$.
\end{abstract}

Keywords: Tuberculosis, tuberculin skin test, epidemiology, Greece.

\section{INTRODUCTION}

The World Health Organization (WHO) declared that the worldwide incidence of new cases of tuberculosis (TB) is estimated to be 8.8 million per year, with 1.5 million deaths every year [1]. Approximately one third of the world's population is infected by mycobacterium tuberculosis. Among infectious diseases, tuberculosis (TB) is the second leading cause of death $[2,3]$. TB cases develop from a large and widely distributed reservoir of latent infection, such that the true incidence of TB does not usually vary greatly across small areas or short periods of time (less than 5 years). The tuberculin survey still remains an epidemiological tool to evaluate TB trends [4]. Although there are immunological tests that determine the production of IFN-gamma by TBspecific T lymphocytes after encountering M. Tuberculosis antigens and even if they have enough benefits (highly specific) over the common test, they are less sensitive than the tuberculin skin test for indicating whether a person has ever been infected. So there are still questions that remain unanswered $[5,6]$. The annual risk of Tuberculosis infection

*Address correspondence to this author at the Department of Respiratory Medicine, General Panarkadian Hospital, Terma Erythrou Stavrou St, 22100 Tripolis, Greece; Tel: (+30) 2713601842; Fax: (+30) 2710222807;

E-mail: gvlachou@gmail.com
(ARTI) is an epidemiological indicator derived by tuberculin skin test (TST) research to measure the size of TB transmission in a community [7]. It is the probability of acquiring new tuberculosis infection or re-infection in a year. ARTI tendencies are a critical index for improvement, or lack thereof, in tuberculosis control in a community. Recently in the past, ARTI assessments were used by TB audit programs to evaluate the incidence of smear positive $\mathrm{TB}$ at a population level by using the Styblo rule [8]. Furthermore, ARTI tendencies have been used to estimate the impact of the HIV epidemic on TB transmission $[9,10]$. In spite of the huge experience which was acquired throughout the past century, the operating characteristics of the TST assure us that there will always exist an exchange between sensitivity and specificity so that these will differ with the prevalence of infection with $M$. tuberculosis and other mycobacteria, or Bacille Calmette-Guerin (BCG) among the population. The predictive value of the test will also depend on the prevalence of tuberculous infection in the particular population [11]. Recent discussions have focused both on the usefulness of new technologies to define who is infected [12] and on more advanced statistic methodologies in the interpretation of TST data to evaluate the infection prevalence [13-15]. 
This survey evaluated the prevalence of Tuberculosis infections and ARTI among young Hellenic recruits of all the geographical areas in Greece. This survey also examined the effect of BCG vaccination on prevalence of infection estimates. Previous studies to evaluate the annual risk of Tuberculosis infection (ARTI) in young Hellenic men was conducted during 1981-1991 in Greece [16].

\section{MATERIAL AND METHODS}

Setting: This research was conducted in Tripolis, Greece, which is where the boot camp of the Hellenic Air Force is currently located, between November 2006 and November 2007.

Population: The research was conducted among a population of 7.492 males recruited for military service which is mandatory for all males in Greece. During enlistment, recruits are obligated to undergo a chest x-ray, an ordinary physical examination and a tuberculin skin test (TST).

Sample size: All recruits from the described period were enrolled.

\section{Methodology}

Type of study: epidemiological observational study.

\section{Study Protocol}

Epidemiological data regarding age, geographic area of residence, TB symptoms, family history of TB, smoking habits, family size, educational level, and parental occupation was collected using structured questionnaires. Any contact (live in the same house or stay together or work together many hours a day) with immigrants from high incidence TB countries was taken into consideration. The data was computerized and further checked for correctness.

Physical examination: All recruits were examined for previous bacill Calmette-Guerin vaccination through BCG scar. They were comprised in the research whether they had a BCG scar or not. Confirmation of the presence of a BCG vaccination was done by a study team member by counter checking on the child vaccination card of each subject (not all vaccinated with BCG develop a scar and the scar may subside as time passes).

Instrumentation: The skin test was performed by using two Tuberculin Units of PPD RT23 with Tween, which were provided by the Statens Serum Institute of Copenhagen, Denmark and followed the specific guidelines during the conduction of the test [17]. Forty eight hours later the transverse diameter of induration which arose was measured by the study nurse and confirmed by the study doctor, thus ensuring test validity. Infection prevalence was determinate by using $10 \mathrm{~mm}$ cut-off points. The $10 \mathrm{~mm}$ criterion is the most widespread used which takes into consideration all reactions $\geq 10 \mathrm{~mm}$ of being an indicator of infection (positive TST) $[18,19]$.

Tool definition: The Annual Risk of Tuberculosis Infection (ARTI). It was defined as $\mathrm{R}=1-(1-\mathrm{P})^{1 / \alpha}$, where $\mathrm{R}$ is the probability of being infected in one year, $\mathrm{P}$ is prevalence of (TB) infection and $\alpha$ the mean age of recruits [7].
Statistical evaluation: The effect of BCG in rendering the tuberculin skin test positive was ascertained by comparing the rates with positive tuberculin skin test between groups with or without BCG. The rates were compared with the use of the $\chi^{2}$ test, and where necessary (few observations), using Fisher's exact test. A p-value $<0.05$ was considered statistically significant. In addition, logistic regression was used in order to take into account other factors, a family history of tuberculosis, BCG history, smoking, number of cigarettes per day and years of smoking, contact with people from each of the "high risk" regions (i.e. Balkans, Eastern Europeans, people from the former Soviet Union, Asians and Africans) and the age of the recruits. The logistic model took the form: $\log \left(\mathrm{P}_{+} / \mathrm{P}_{-}\right)=\beta_{0}+\beta_{1} \mathrm{X}_{1}+\beta_{2} \mathrm{X}_{2}+\beta_{3} \mathrm{X}_{3}+\ldots$ where $\mathrm{P}_{+}$, $\mathrm{P}_{\text {., }}$ are the probabilities of positive and negative tuberculin skin test and $X_{1}=1$ if the recruit had BCG vaccination and 0 , if not, $X_{2}$ the family history of tuberculosis, $X_{3}$ the age of the recruit, and similarly for the rest of the variables. Data was analyzed by using SPSS for Windows version 13.0.

For the aim of our analysis the residential areas were divided into urban and rural which was calculated with data provided from the National Statistical Service of Greece according to the 2001 population census (National Statistical Service, http://www.statistics.gr/portal/page/portal/ESYE).

The research protocol was confirmed by the Medical Directorate of the Hellenic Air Force General Staff. Written informed consent to participate in the study was acquired from all participants.

The research protocol was approved by the Ethics committees of the University of Thessaly.

\section{RESULTS}

The tuberculin skin test was conducted to 7.492 young men. The recruits' mean age was 23.57 years (standard deviation was 3.05) (Table 1).

\section{Table 1. Annual Risk of Tuberculosis Infection (ARTI)}

\begin{tabular}{|c|c|c|c|c|}
\hline \multirow{3}{*}{ BCG } & & Age & $\begin{array}{c}\text { Positive Tuberculin } \\
\text { Skin Test }\end{array}$ & ARTI \\
\hline \hline \multirow{3}{*}{ Not Vaccinated } & Rural & 21.71 & 0.0467 & 0.00220 \\
\cline { 2 - 5 } & Urban & 24.23 & 0.0474 & 0.00200 \\
\cline { 2 - 5 } & Total & 23.85 & 0.0474 & 0.00203 \\
\hline \multirow{3}{*}{ Total } & Rural & 21.64 & 0.1984 & 0.01017 \\
\cline { 2 - 5 } & Urban & 23.75 & 0.2169 & 0.01024 \\
\cline { 2 - 5 } & Total & 23.41 & 0.2138 & 0.01022 \\
\hline & Rural & 21.66 & 0.1451 & 0.00721 \\
\cline { 2 - 5 } & Urban & 23.92 & 0.1547 & 0.00700 \\
\cline { 2 - 5 } & Total & 23.57 & 0.1531 & 0.00702 \\
\hline
\end{tabular}

BCG vaccination was statistically associated with presence of TST positivity (p-value $<0.0005$ Fisher's Exact Test, odds ratio [OR]:1.56).

Among the recruits $63.6 \%$ were $\mathrm{BCG}$ vaccinated while $36.4 \%$ were not.

$15.3 \%$ of the recruits had a tuberculin skin test which was positive. 
BCG vaccination was statistically associated with presence of TST positivity (p-value $<0.0005$ Fisher's Exact Test, odds ratio [OR]:1.56).

The ARTI in the non- vaccinated group was $0.2 \%$ (Table 1, Fig. 1).

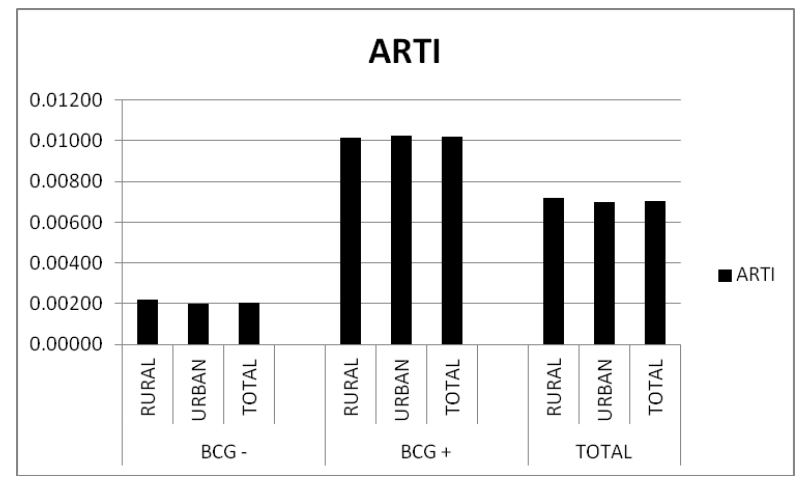

Fig. (1). Overview of individual screened by BCG vaccination status. $\mathrm{BCG}-=$ Not $\mathrm{BCG}$ vaccinated. $\mathrm{BCG}+=\mathrm{BCG}$ vaccinated. The ARTI in the non vaccinated group was $0.2 \%$ while the ARTI in the vaccinated group was $1 \%$. The ARTI concerning all recruits was $0.7 \%$.

There were not any statistically significant differences between urban and rural population concerning the positivity of the tuberculin skin test $(p$-value $=0.425)($ Fig. 2).

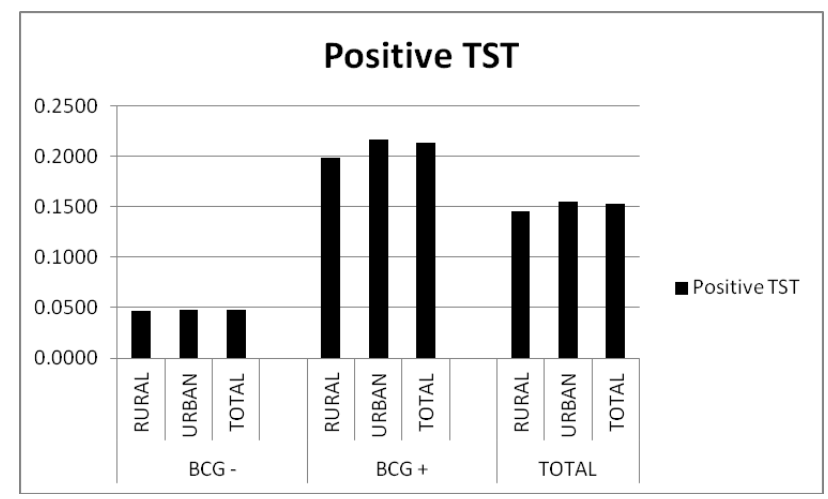

Fig. (2). $B C G-=$ Not $B C G$ vaccinated. $B C G+=B C G$ vaccinated. TST $=$ Tuberculin skin test. There were not any statistically significant differences between urban and rural population concerning the positivity of the tuberculin skin test $(\mathrm{p}$-value $=$ 0.425 ). BCG vaccination was statistically associated with presence of TST positivity (p-value $<0.0005$ Fisher's Exact Test).

Differences in the positivity of the tuberculin skin test among the recruits not BCG vaccinated, in recent contact with immigrants from high incidence countries, were not statistically significant (Fig. 3).

\section{DISCUSSION}

Pulmonary Tuberculosis (TB) is on increase in world prevalence and significantly menaces the population of both developed and under developed countries [20]. The proliferation of tuberculosis due to the absence of suitable and decidedly responsive intervention strategies and programs [20]. Target tuberculin testing for LTBI is a main component of tuberculosis (TB) control which allow us to identify people at high risk, or people at low risk whose future activity will put them at an increased risk of exposure, of developing TB who would profit by treatment of LTBI if detected. The TST remains one of the standard test of preference for the diagnosis of LTBI in large and presumably healthy populations such those of this study, at least until IGRA becomes available.

Identification and therapy for persons with latent infection constitute a necessary factor of the TB elimination strategy supported by the Hellenic Air Force.

The method which was used in this survey is the tuberculin skin test, or Mantoux. It employs a purified protein derivative which is injected intradermally into the volar surface of the subjects arm. The individuals who have already been exposed to TB will develop an induration on the side of the injection within 48 hours. An induration is an indication that their body has reacted to the antigens in the purified protein derivative [20]. It is required observation within 48 to 72 hours in order to test read, the test does not discriminate latent from active tuberculosis but indicates a TB infection.

The advantage of TST is that it is a test that can be performed by front-line health care workers, and does not require specialized laboratory setting.

A positive TST reaction may present latent TB infection, previous BCG vaccination, or a cross-reaction to non tuberculous mycobacteria. Guidelines by the American Thoracic Society (ATS) warn against taking former BCG vaccination into consideration when interpreting a TST reaction [21]. So this analysis was restricted to recruits without $B C G$ vaccination, to avoid any $T B$ sensitivity induced by BCG vaccination.

The statistically significant difference in the ARTI rates of this study, between the BCG vaccinated (ARTI $=1 \%$ ) and not vaccinated (ARTI $=0,2 \%$ ) recruits is an indication of the increasing effect of the BCG to the tuberculin skin test reaction.

BCG vaccine is currently used in Greece (during childhood, ages of 5 to 7 years) to protect infants and children from severe TB infection, particularly TB meningitis. It does not confer lifelong immunity, and its significance in persons receiving the TST causes confusion [22].

The leading deduction of this survey is that contrasted to former available epidemiological data from Greece, there has been an important decline in the prevalence of TST positivity in Greek enlistees during the last 30 years. Bouros et al. previously stated a decline of TST positivity from $14,2 \%$ in 1981 to $6,8 \%$ in $1991[16,23,24]$. The prevalence of TST positivity in this survey is $4,74 \%$ (in recruits without BCG vaccination), and the ARTI is $0,2 \%$.

The test population of these recruits was preferred due to their accessibility and the fact that they came from different geographical areas of the country rendering the sample representative of Greece.

This survey has a particular interest in comparing specific groups of the population (such as urban versus rural). 


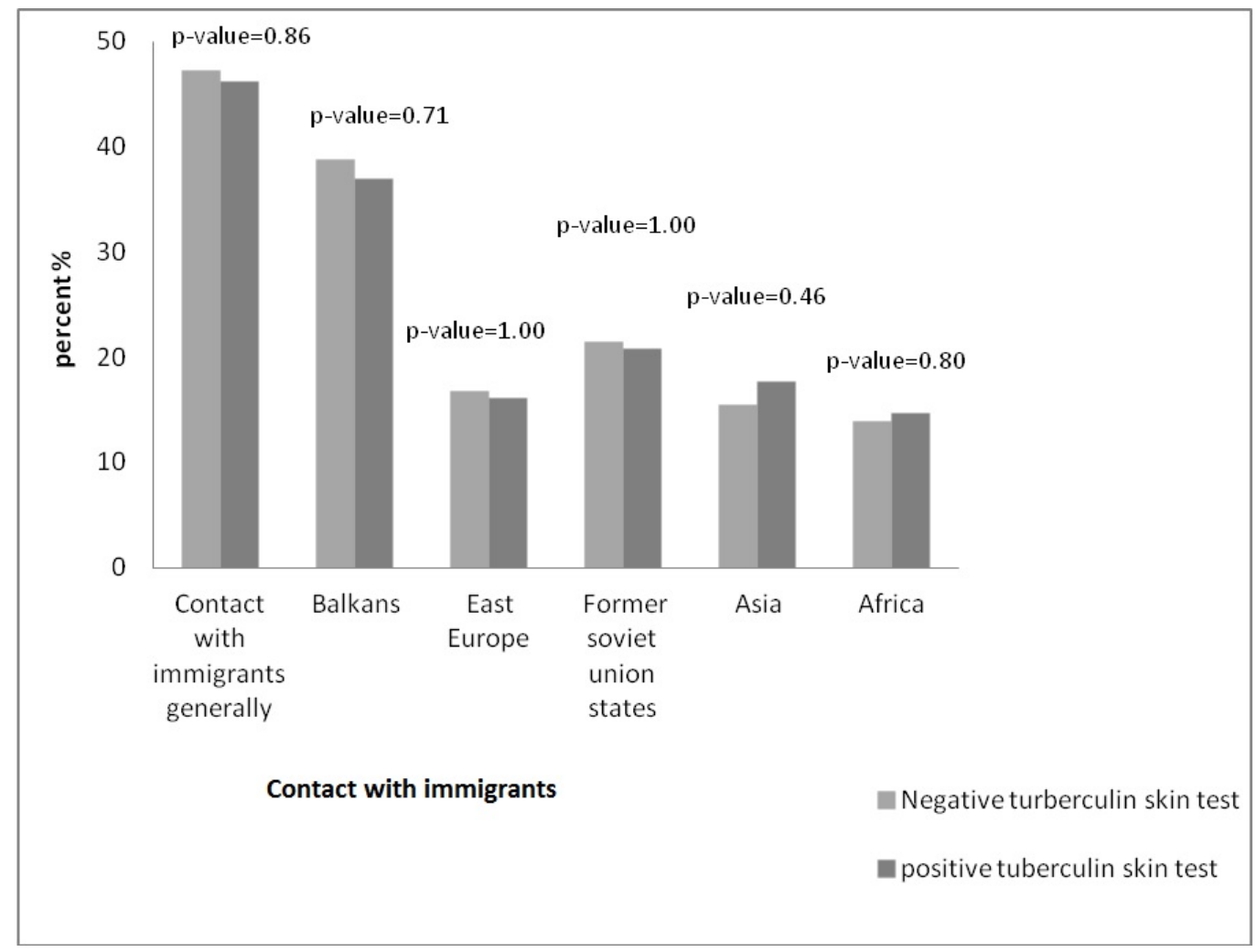

Fig. (3). Differences in the positivity of the tuberculin skin test among the recruits not BCG vaccinated in recent contact with immigrants from high incidence countries were not statistically significant.

One more significant deduction of the survey is that residency in rural areas of Greece was not found to be an independent predictor of the appearance of TST reactivity in the multivariable analysis.

Human migration has had a significant effect on spreading tuberculosis throughout human history. Nowadays, geographic obstacles have been easily overcome, and mass migration reached unprecedented levels in the last half of the $20^{\text {th }}$ and the outset of the $21^{\text {st }}$ centuries [25].

Immigrants and refugees coming from high incidence countries of Asia, Africa, the former USSR, Balkan and the former Eastern Bloc, depict one of the leading "reservoir" of tuberculosis, frequently resistant to numerous antituberculous drugs [26, 27].

An important deduction of the survey is that there were not any statistically significant differences among the population in recent contact with immigrants from high incidence countries.

The analysis has some important limitations, which have been underlined by the authors. False positive reactions may be attributed to non tuberculous mycobacteria exposure [28, 29]. Contrary, false negative reactions may occur to people with suppressed or altered immunity, given that TST reactions are based on a cell-mediated immune response [30].

Finally, these results cannot be extrapolated to other population groups (the elderly, females) since this study included only healthy young males; individuals with risk factors for TB (diabetes mellitus, HIV, immunodeficiency, hematological malignancies) are not enlisted into the Hellenic Air Force. The study recruits comprised a sample of the male population of that age in Greece, as enrollment in the Greek Air Force is mandatory for every male over the age of 18, coming from every geographical part of Greece (urban or rural).

The identification of people with positive TST may be used as an indirect assessment for the overall disease burden, as these patients-after elimination of those vaccinated against TB-represent a potential "reservoir" of Mycobacterium Tuberculosis. The Hellenic Armed Forces have taken part actively in the Federal Operations versus TB for the last 70 years. Serial surveys on the TST positivity in enlistees can be used as an indicator of the temporal epidemiological trends of mycobacterial burden in the population in time. The results encourage the idea that Greece has acted seriously in order to reduce the TB disease burden.

\section{CONCLUSION}

The determination of changes in the risk of infection is the most informative indicator for changes in transmission patterns of M. tuberculosis in a community [7].

Obviously, the analysis demonstrates further decline in the prevalence of TST positivity in young Hellenic enlistees compared to the outcomes of former studies on this population.

Prevalence of tuberculosis infection and annual risk of TB infection estimated from tuberculin surveys is considered the best epidemiological index available to monitor the TB situation in a community [17]. 
The methodology of evaluating infection prevalence and the annual risk of infection itself is debatable and doubtful [30]. However tuberculin surveys supply significant information, particularly on the trend of the TB problem [4].

Until more accurate diagnostic tests are available, the results suggest that TST (if accurately utilized) is useful additionally to routine screening.

\section{AUTHOR CONTRIBUTION}

Professor K. Gourgoulianis contributed to the concept and design of the study, and provided critical comments for the manuscript.

V. Skoufaras provided the questionnaire and assisted in data collection.

I. Gerogianni provided critical comments for the manuscript.

G. Vlachou conducted and analyzed the data from this evaluation, and also drafted the manuscript.

\section{ABBREVIATIONS}

$$
\begin{array}{ll}
\mathrm{TST} & =\text { Tuberculin Skin Test } \\
\mathrm{TB} & =\text { Tuberculosis } \\
\mathrm{ATS} & =\text { American Thoracic Society } \\
\text { ARTI } & =\text { Annual Risk of Tuberculosis Infection } \\
\mathrm{BCG} & =\text { Bacill Calmette-Guerin } \\
\text { LTBI } & =\text { Latent Tuberculosis Infection } \\
\text { WHO } & =\text { World Health Organization } \\
\text { IFN } & =\text { Interferon } \\
\text { PPD } & =\text { Purified Protein Derivative } \\
\text { USSR } & =\text { Union of Soviet Socialist Republics } \\
\text { IU } & =\text { International Units } \\
\text { IGRA } & =\text { Interferon Gamma Release Assay }
\end{array}
$$

\section{CONFLICT OF INTEREST}

The authors confirm that this article content has no conflict of interest

\section{ACKNOWLEDGEMENTS}

The authors thank the Medical Directorate of the Hellenic Air Force General Staff for permitting the conduction of the survey. They also thank the Training Centre of the Hellenic Air Force in Tripolis for their overall support. The authors thank Dr Yiatromanolakis N, for providing the questionnaire. They also are grateful to $\mathrm{Dr}$ Saridis N, Dr Lambaditis I, Dr Doulgerakis N, for their help in collecting data. They also thank Spala D, Saradaki K, Mpriasouli B, and Tsaprounis I, who assisted in data collection. The authors acknowledge Stamatopoulou A and Lyberopoulos A for their kind cooperation.

\section{REFERENCES}

[1] World Health Organization. Global tuberculosis control 2011. WHO/HTM/TB/2011.16.Geneva, Switzerland: WHO, 2011.

[2] Raviglione MC, Snider DE Jr, Kochi A. Global epidemiology of tuberculosis. Morbidity and mortality of a worldwide epidemic. JAMA $1995 ; 273: 220-226$.
[3] World Health Organization. Multidrug and extensively drug resistant TB (M/XDR-TB). 2010 Global Report on Surveillance and Response. Geneva, World Health Organization, 2010.

[4] Borgdorff M. Annual risk of tuberculosis infection-time for an update. Bulletin of the World Health Organization: The International Journal of Public Health 2002; 80: 501-502.

[5] Harada N. Characteristics of diagnostic method for tuberculosis infection based on whole blood interferon-gamma assay. Kekkaku 2006 Nov; 81 (11): 681-686.

[6] Moran-Medoza O. Interferon- $\gamma$ release assays for the diagnosis of latent Mycobacterium tuberculosis infection. ERJ 2001; 38: 1237 1242.

[7] Rieder H. Annual risk of infection with mycobacterium tuberculosis. ERJ 2005; 25: 181-185.

[8] Styblo K (1985) The relationship between the risk of tuberculous infection and the risk of developing infectious tuberculosis. Bull Int Union Tuberc 60: 117-9.

[9] Egwaga SM, Cobelens FG, Muwinge H, Verhage C, Kalisvaart N, et al. (2006) The impact of the HIV epidemic on tuberculosis transmission in Tanzania. AIDS 20: 915-21.

[10] Odhiambo JA, Borgdorff MW, Kiambih FM, Kibuga DK, Kwamanga DO, et al. (1999) Tuberculosis and the HIV epidemic: increasing annual risk of tuberculous infection in Kenya, 19861996. Am J Public Health 89: 1078-82.

[11] Huebner RE, Schein MF, Bass JBJ (1993) The tuberculin skin test. Clin Infect Dis 17: 968-75.

[12] Pai M, Riley LW, Colford JM (2004) Interferon-gamma assays in the immunodiagnosis of tuberculosis: a systematic review. Lancet Infect Dis 4: 761-76.

[13] Rieder HL (1995) Methodological issues in the estimation of the tuberculosis problem from tuberculin surveys. Tuber Lung Dis 1995; 76: 114-21.

[14] Neuenschwander BE, Zwahlen M, Kim SJ, Engel RR, Rieder HL (2000) Trends in the prevalence of infection with Mycobacterium tuberculosis in Korea from 1965 to 1995: an analysis of seven surveys by mixture models. Int J Tuber Lung Dis 4: 719-29.

[15] Pai M, Dendukuri N, Wang L, Joshi R, Kalantri S, et al. (2008) Improving the estimation of tuberculosis infection prevalence using T-cell-based assay and mixture models. The International Journal of Tuberculosis and Lung Disease 12: 895-902.

[16] Bouros D, Demoiliopoulos I, Moschos M, et al. Tuberculin sensitivity trends in Hellenic army recruits during the period 198191. Tuber Lung Dis. 1995; 76:126-129. doi: 10.1016/09628479(95)90554-5. [PubMed] [Cross Ref].

[17] Arnadotir T, Rieder HL, Trébucq A, Waaler HT. Guidelines for contacting tuberculin skin test surveys in high prevalence countries. Tubercle Lung Disease 1996; 77 (suppl): 1-20.

[18] Wang L, Turner MO, Elwood RK, Schulzer M, FitzGerald JM (2002) A meta-analysis of the effect of Bacille Calmette Guerin vaccination on tuberculin skin test. Thorax 57: 804-9.

[19] Bowerman RJ (2004) Tuberculin skin testing in BCG-vaccinated populations of adults and children at high risk for tuberculosis in Taiwan. Int J Tuberc Lung Dis 8(10): 1228-33.

[20] Crawford LS, Romanisk SN. The virulence of tuberculosis in developed and developing countries. Global Journal of Health Science 2011; 3: 77-89.

[21] Targeted tuberculin testing and treatment of latent tuberculosis infection. American Thoracic Society. MMWR Recomm Rep. 2000 Jun $9 ; 1-51$.

[22] Centers for Diasease Control and Prevention: Target Tuberculosis Testing and Interpreting Tuberculin Skin Tests Results.

[23] Bouros D, Demoiliopoulos J, Panagou P, et al. Incidence of tuberculosis in Greek armed forces from 1965-1993. Respiration 1995; 62: 336-340 [ Pub Med].

[24] Bouros D, Zeros G, Demoiliopoulos J, Economopoulos A. The course of tuberculin index in Greek soldiers. II Panhellenic Pulmonary Congress Athens: 6-8 December 1985; p 80 (Abstract).

[25] Blumberg H, Migliori G, Ponomarenko O, Heldal E. Tuberculosis on the move. The Lancet 2010; 375: 2127-2129.

[26] Rieder H L, Zellweger J P, Raviglione M C, Keizer S T, Migliori GB. Tuberculosis control in Europe and international migration. Eur Respir J 1994; 7: 1545-1553.

[27] Kanavaki S, Mantadakis E, Nikolaou S, Papavassiliou A, Karambela S, Anagnostou S, Falagas ME, Samonis G: Trends in antimicrobial resistance of $M$. tuberculosis isolates over the decade 
1993-2002 from different populations in Greece. Int J Tuberc Lung Dis 2006, 10:559-564. PubMed Abstract.

[28] Lee E, Holzman RS. Evolution and current use of the tuberculin test. Clin Infect Dis 2002; 34: 365-370.

Received: September 11, 2013

(C) Garyfalia et al.; Licensee Bentham Open.

This is an open access article licensed under the terms of the Creative Commons Attribution Non-Commercial License (http://creativecommons.org/licenses/by-nc/3.0/) which permits unrestricted, non-commercial use, distribution and reproduction in any medium, provided the work is properly cited. 